\title{
Seroprevalence and trend of Hepatitis B virus infection among the blood donors of North Karnataka: A Nine Year Study
}

\author{
Giriyan S.S ${ }^{1}$, Nirala N.K ${ }^{2}$, Agrawal A ${ }^{3}$, Bajpai $R^{4}$ \\ ${ }^{1}$ Dr. Sujata S. Giriyan, Professor \& HOD, ${ }^{2}$ Dr. Niraj Kumar Nirala, Post Graduate Resident, ${ }^{3}$ Dr. Akansha Agrawal, Post \\ Graduate Resident, ${ }^{4}$ Dr. Richa Bajpai, Post Graduate Resident, all authors are affiliated with Department of Pathology, \\ KIMS, Hubli, Karnataka, India.
}

Address for Correspondence: Dr. Niraj Kumar Nirala, Email: nirajkn@gmail.com

\begin{abstract}
Introduction: Hepatitis B is one of the leading transfusion transmissible infections. The prevalence of this infection varies across the different geographical areas with intermediate prevalence in India. Studying the trend in seroprevalence is useful to assist the preventive strategies. The aim of this study was to determine the trend of seroprevalence of hepatitis B in North Karnataka region over a nine-year period (2007-2015). Materials \& Methodology: The study was conducted at one of the largest blood banks of Northern Karnataka of an apex health care institution serving predominantly the people of North Karnataka. A retrospective analysis of blood donors over a period of nine years (2007-2015) was done to assess the seroprevalence and the trend of hepatitis B infection among them. ELISA was used to detect the hepatitis B surface antigen in the donors as a marker of infection. Results: A total of 80,312 blood donors were undertaken for the study. About 1613 (2\%) were positive for HBsAg, which falls under the "intermediate prevalence (2\%-7\%) zone" as per World Health Organization (WHO) guidelines. An increasing trend in first five years (2007-2011) and then decreasing trend over next four years (2012-2015) was observed in the present study. Replacement donors and male blood donors showed significantly higher seropositivity compared to voluntary donors and female donors respectively. Conclusion: North Karnataka has an intermediate prevalence of hepatitis B in blood donors with increasing trend in initial five years and decreasing trend over the last four-year period.
\end{abstract}

Keywords: HBsAg, Seroprevalence, Blood donors, Hepatitis B

\section{Introduction}

Hepatitis B virus (HBV) infection is a leading cause of acute and chronic liver disease [1]. The infected person has higher risk of probability for cirrhosis and liver cancer. Approximately $30 \%$ of the world's population or about 2 billion persons have serological evidence of either current or past infection with hepatitis B virus [2]. The prevalence of chronic HBV infection in India ranges from $2 \%$ to $10 \%$ as shown by different studies [2].

Hepatitis B infection transfusion transmissible infections; which demands for meticulous pretransfusion testing and screening for HBsAg [3]. Millions of lives are saved every year through blood transfusion; provision of safe blood is of paramount

Manuscript received: $10^{\text {th }}$ June 2017

Reviewed: $20^{\text {th }}$ June 2017

Author Corrected: $28^{\text {th }}$ June 2017

Accepted for Publication: $5^{\text {th }}$ July 2017 importance for any health care delivery system. Burden of the disease and loss of life resulting from unsafe blood transfusions is very serious problem for the communities in developing countries.

The improved screening and testing of blood donors will significantly reduced transfusion transmitted diseases in most countries. The disease trends and blood assessment can better be done by the study of seroprevalence rate of hepatitis B in blood donors and indexed accurately in general population [4].

The present study was carried out with the aim to find out the seroprevalence of Hepatitis B and its trend among the blood donors a hospital based blood transfusion service set up in northern Karnataka over a period of nine years. 


\section{Materials and Method}

This prospective observational study was carried out at the Blood Bank (under Department of Pathology), Karnataka Institute of Medical Sciences, a tertiary care Government hospital, retrospectively from January 1, 2007 to December 31, 2015 over a period of nine years. This blood bank is one of the largest blood banks of the state of Karnataka and caters to entire Northern Karnataka. The experiment on data size 80312 donors who donated blood during the nine years were conducted as in given below

Step I- Clinically healthy individuals of age group (18$60 \mathrm{yrs}$ ), body weight ( $>45 \mathrm{~kg}$ ), hemoglobin (>12.5 g/dl) and not donated blood in the last three months is the qualification criteria for blood donation in the study group.

Step II-Sera of these qualified blood donors are screened for hepatitis B surface antigen (HBsAg) using standard Enzyme Linked Immunosorbent Assay (ELISA) kits.

Step III-The procedure of test is followed according to manufacturer's instruction. Samples showing reactivity are considered positive.
All apparently healthy blood donors (voluntary/ replacement) who donated blood at this hospital during the study period were included for the study. People who donate blood without expecting any favor in return or in voluntary blood donation camps were classified as voluntary blood donors.

The replacement donors were the friends or relatives, recruited by patients or their relatives to replace blood used or expected to be used for the patients from the blood bank.

Information regarding gender, number of previous donations, and type of donation (replacement / voluntary) and HBsAg status of each donor was obtained from the records. Data were entered in Microsoft Excel and analyzed by using Epi Info 7 statistical package. Prevalence of HBV was noted with respect to gender, type of donor and year.

Significance of the seroprevalence according to gender and type of donor was determined by chi square test. $\mathrm{P}$ value $<0.05$ was considered to be statistically significant.

\section{Results}

The data of 80312 donors who donated blood during the nine years study period were analyzed. Among them, 77306 $(96.25 \%)$ were male donors and 3006 (3.75\%) were female donors. Replacement donations 50735 (63.2\%) were the majority whereas, only 29577 (36.8\%) donations were from the voluntary donors (Table 1)

Table-1: Gender wise and type of donor distribution during the nine-year study period.

\begin{tabular}{|c|c|c|c|c|c|}
\hline \multirow{2}{*}{ Year } & \multicolumn{2}{|c|}{ Voluntary Donors } & \multicolumn{2}{c|}{ Replacement Donors } & \multirow{2}{*}{ Total Donors } \\
\cline { 2 - 5 } & Male & Female & Male & Female & $\mathbf{8 4 6 0}$ \\
\hline $\mathbf{2 0 0 7}$ & 3083 & 319 & 5006 & 52 & $\mathbf{8 3 7 6}$ \\
\hline $\mathbf{2 0 0 8}$ & 2728 & 263 & 5314 & 72 & $\mathbf{1 0 5 0 3}$ \\
\hline $\mathbf{2 0 0 9}$ & 2340 & 183 & 7908 & 83 & $\mathbf{8 5 1 7}$ \\
\hline $\mathbf{2 0 1 0}$ & 2271 & 183 & 5980 & 33 & $\mathbf{8 7 2 0}$ \\
\hline $\mathbf{2 0 1 1}$ & 3072 & 277 & 5338 & $\mathbf{9 2 1 4}$ \\
\hline $\mathbf{2 0 1 2}$ & 4667 & 345 & 4180 & 48 & $\mathbf{8 4 2 5}$ \\
\hline $\mathbf{2 0 1 3}$ & 2959 & 299 & 5119 & 54 & $\mathbf{8 6 6 0}$ \\
\hline $\mathbf{2 0 1 4}$ & 3291 & 312 & 5003 & 109 & $\mathbf{9 4 3 7}$ \\
\hline $\mathbf{2 0 1 5}$ & 2704 & 281 & 6343 & $\mathbf{5 4 4}$ & $\mathbf{8 0 3 1 2}$ \\
\hline Total & $\mathbf{2 7 1 1 5}$ & $\mathbf{2 4 6 2}$ & $\mathbf{5 0 1 9 1}$ & & \\
\hline
\end{tabular}


Table 2: shows the seroprevalence of HepB among replacement donors is $2.32 \%$ which is comparatively higher than the seroprevalence among voluntary donors $(1.46 \%)$. This difference was found to be statistically highly significant $(\mathrm{p}<0.0001)$. The seroprevalence of HepB among male donors was $2.06 \%$ as compared to only $0.56 \%$ among female donors, which was statistically highly significant $(\mathrm{p}<0.0001)$. The overall prevalence in 80312 blood donors was $2 \%$.

Table 2: Seroprevalence of Hepatitis B in different categories of blood donors.

\begin{tabular}{|c|c|c|c|c|}
\hline Variables & Total & $\begin{array}{c}\text { HBsAg positive } \\
\text { No. }(\%)\end{array}$ & Chi square & P value \\
\hline \multicolumn{5}{|l|}{ Type of Donor } \\
\hline Voluntary Donor & 29577 & $432(1.46 \%)$ & \multirow[t]{2}{*}{70.75} & \multirow[t]{2}{*}{$<0.0001$} \\
\hline Replacement Donor & 50735 & $1181(2.32 \%)$ & & \\
\hline Total & 80312 & $1613(2) \%$ & & \\
\hline \multicolumn{5}{|l|}{ Gender of Donor } \\
\hline Male & 77306 & $1596(2.06 \%)$ & \multirow[t]{2}{*}{32.28} & \multirow[t]{2}{*}{$<0.0001$} \\
\hline Female & 3006 & $17(0.56 \%)$ & & \\
\hline Total & 80312 & $1613(2 \%)$ & & \\
\hline
\end{tabular}

Fig 1; shows the trend of seroprevalence of Hepatitis B in the nine years study period. As shown, the seroprevalence of Hepatitis B among blood donors was $1.87 \%$ in the year 2007, 1.75\% in 2008 and 1.81\% in 2009. However there was an increase in the seroprevalence through the first four years till 2011 and then showing a significant decrease in the trend of seroprevalence by the end of study period i.e ; 2015 .

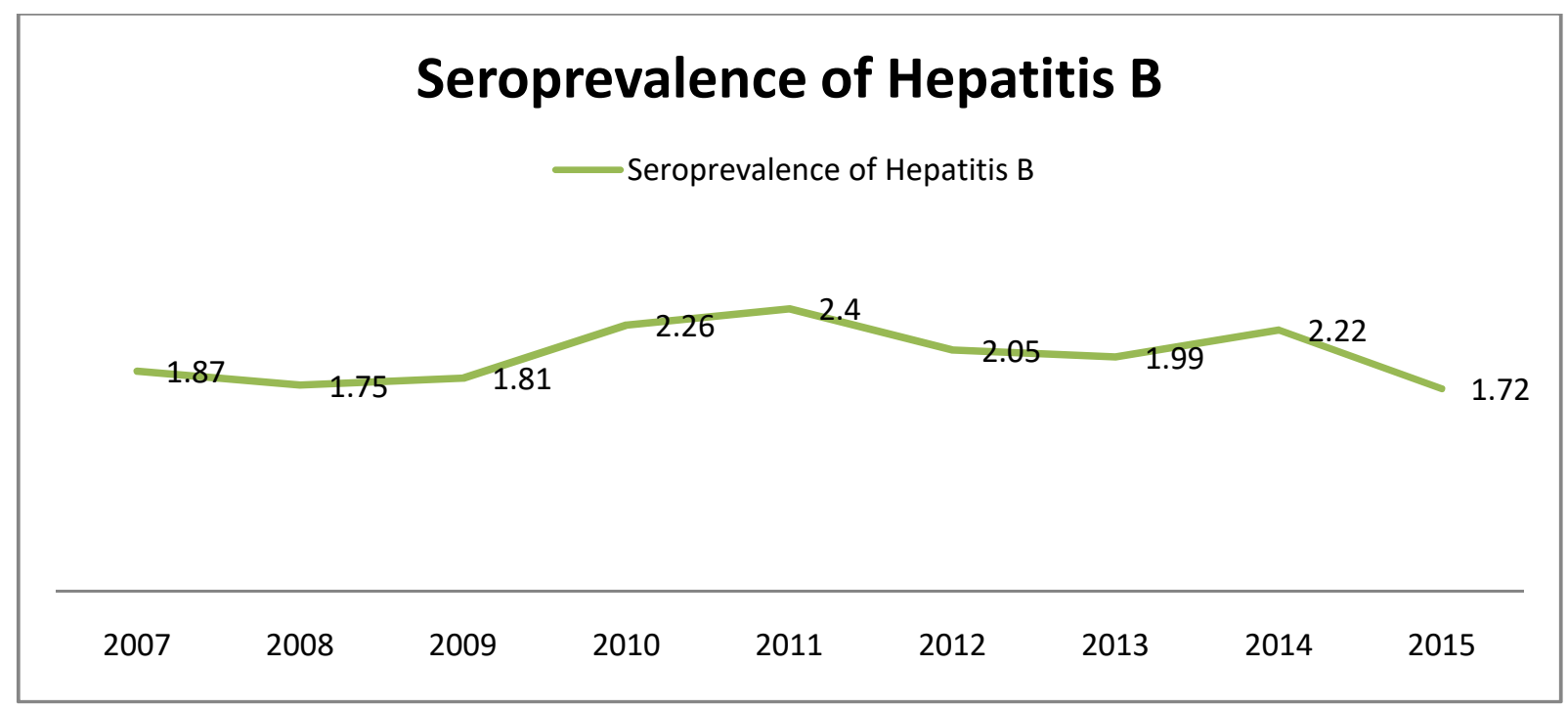

Fig-1: Trend of Seroprevalence of Hepatitis B in the study period.

\section{Discussion}

In the present retrospective study, a total of data of 80312 blood donors were analyzed. Majority of the donors were males $(96.25 \%)$ and the rest $3.75 \%$ were female donors. Similar findings observed by other studies include Fernandes et al [3], Rose et al. [4] in Vellore, Arora D et al [5]. in Southern Haryana, Singh $\mathrm{K}$ et al [6] in Coastal Karnataka, Pahuja et al [7] in Delhi and Singh B et al [8] noting more than $90 \%$ of the male donors. However, the statistical analysis (chisquare test) revealed the difference in the seroprevalence according to the gender to be significant ( $p$ value $<0.0001$ ). A significantly higher HBsAg seroprevalence in males than in females is also reported in other studies $[8,9]$. In the present study, of the total blood donors Voluntary Donors constituted $36.8 \%$, while Replacement Donors were $63.2 \%$. It is 
Research Article

shown that replacement donors constitute the largest group of blood donors in India [10], reflecting the lack of awareness amongst the general population. This is similar to study done by Singh et al. (82.4\%) [6], Kakkar et al. (94.7\%) [12], Pahuja et al. (99.48\%) [7] and Arora et al. (68.6\%) [13]. In contrast study done by Bhattacharya et al [14] who has noticed a predominance of Voluntary Donor.

The present study revealed that HBV infection was more prevalent among replacement blood donors than voluntary donors as noted in the study of Sonwane et al. and Singhvi et al. $[15,16]$. According to India's Drugs and Cosmetics Act (1945), each blood unit has to be tested for hepatitis B virus infection [17]. In our study the overall prevalence of Hepatitis B was found to be 2\%, comparable to study done by Sri Krishna et al. [18] in Bangalore. India has been placed in the intermediate zone of prevalence of hepatitis B by the World Health Organization (2-7\% prevalence rates) with a $\mathrm{HbsAg}$ prevalence rate of $1-2 \%$ reported by Lodha et al. [7].

Supporting this, HbsAg prevalence in Punjab blood donors was 1.7\% [19], while Rajasthan had 3.44\% [20] and Delhi had 2.23\% [7]. In Karnataka, coastal area [6] had $0.62 \%$ of HBV seropositivity. Singh et al. have reported a HbsAg prevalence of $1.8 \%$ whereas Joshi and Ghimere have reported a prevalence of $2.71 \%$ in healthy Nepalese males $[8,9]$. On the other hand, the prevalence of $\mathrm{HBV}$ infection is lower in the United States and Western Europe $(0.1-0.5 \%)$ and is reported to be higher, 5-15\% in South East Asia and China [7].

One of the greatest challenges of transfusion medicine is the prevention of transmission of infectious diseases through blood transfusion.8617 donors donated at St. Johns Medical College Hospital Blood bank from 1st. September 1997 to 31st August 1998. Srikrishna et al reported that seropositivity among donors for HIV was $0.44 \%$, for $\mathrm{HBsAg} 1.86 \%$, for $\mathrm{HCV} 1.02 \%$ and for VDRL $1.6 \%$ [18].The magnitude of hepatitis to be far more than that of HIV. Hence testing for HCV routinely is recommended.

Behal et al in their study showed that out of 20,000 donors, $450(2.25 \%)$ were $\mathrm{HBsAg}$ positive (95\% confidence interval (CI), 2.0445-2.4554). Higher prevalence of HbsAg was found among males $(440 / 19235)$ than females (10/765). The age specific prevalence rose from $1.78 \%(108 / 6058)$ in donors aged $19-25$ years to a maximum of $3.03 \%$ (96/3161) in donors aged 35-45 years and decreased in older age groups. The peaks were detected in male donors aged 35-45 years and in females aged 25-35 years. Rhnegative blood group donors (21/873) and Rh-positive group donors (429/19127) had almost equivalent prevalence rates of HBsAg. HBsAg was more prevalent in blood group B donors (174/7426) and less prevalent in AB blood group donors (38/2032) [22].

A retrospective review of donor's record covering the period between 2004 and 2008 at the blood bank, JSS Hospital, Mysore was carried out. All samples were screened for HIV, HBsAg, HCV, syphilis and malaria. Of the $39,060,25,303(64.78 \%)$ were voluntary donors and the remaining 13,757 (35.22\%) were replacement donors. Pallavi et al reported that overall prevalence of $\mathrm{HIV}, \mathrm{HbsAg}, \mathrm{HCV}$ and syphilis were $0.44,1.27,0.23$ and $0.28 \%$, respectively. No blood donor tested showed positivity for malaria parasite.

Majority were voluntary donors with male preponderance. In all the markers tested there was increased prevalence of TTI among the replacement donors as compared to voluntary donors [21]. With the implementation of strict donor criteria and use of sensitive screening tests, it may be possible to reduce the incidence of TTI in the Indian scenario.

The present study revealed a decreasing trend in seroprevalence was noticed over nine years study period. The lower prevalence and decreasing trend may be a result of several factors. The awareness about the disease and modes of prevention may be one reason for the declining trend in HBV infection. Secondly, the implementation of National Blood policy with uniform guidelines and pre-donation counseling and strict donor selection criteria help in excluding the possibly infected donors. The absence of HBsAg in blood donors may not be sufficient to ensure the lack of circulating HBV and hence there are chances of missing occult HBV infection

\section{Conclusion}

Present study showed that most of the donors were replacement donors with male preponderance. There was increased Hepatitis B positivity rate amongst the replacement donors as compared to the voluntary donors. Ensuring the safety of patients by reducing the residual risk of transfusion transmitted hepatitis is the concern of every transfusion center. The decreasing trend of seropositivity reflects the effective safety 
strategy among general population and transfusion medicine services. Apart from these, other factors like public awareness, prohibition of professional blood donation have also contributed to the decrease in trend of Hepatitis B.

There should be an establishment of a nationally coordinated blood transfusion services with the implementation of strict donor selection criteria, use of sensitive screening tests and establishment of strict guidelines for blood transfusion may be helpful to further reduce the incidence of Hepatitis B in India.

Funding: Nil, Conflict of interest: None initiated, Permission from IRB: Yes

\section{References}

1. Lee WM. Hepatitis B virus infection. N Engl J Med. 1997 Dec 11;337(24):1733-45. doi:10.1056/NEJM 199712113372406

2. Prevention of hepatitis B in India, An overview. World Health Organization. New Delhi 2002.

3. Fernandes H, D'souza PF, D'souza PM. Prevalence of transfusion transmitted infections in voluntary and replacement donors. Indian J Hematol Blood Transfus. 2010 Sep;26(3):89-91. doi: 10.1007/s12288-010-00440. Epub 2010 Oct 21.

4. Dolly R, Annie S, Thaiyanayaki P, George PB, Jacob $\mathrm{TH}$. Increasing prevalence of HIV antibody among blood donors monitored over 9 years in blood bank. Indian J Med Res. 1998 Aug; 108:42-44. PMID: 9785677

5. Arora D, Arora B, Khetarpal A. Seroprevalence of HIV, HBV, HCV and syphilis in blood donors in Southern Haryana. Indian J Pathol Microbiol. 2010 Apr-Jun;53(2):308-9. doi: 10.4103/0377-4929.64295.

6. Singh K, Bhat S, Shastry S. Trend in seroprevalence of Hepatitis B virus infection among blood donors of coastal Karnataka, India. J Infect Dev Ctries. 2009 Jun $1 ; 3(5): 376-9$.

7. Pahuja S, Sharma M, Baitha B, Jain M. Prevalence and trends of markers of hepatitis $C$ virus, hepatitis $B$ virus and human immunodeficiency virus in Delhi blood donors. A hospital based study. Jpn J Inf Dis. 2007 Nov; 60:389-391. PMID: 19759508.
8. Singh B, Verma M, Kotru M, Verma K, Batra M. Prevalence of HIV and VDRL seropositivity in blood donors of Delhi. Indian J Med Res. 2005 Sep;122(3): 234-6.

9. Karki S, Ghimire P, Tiwari BR, Rajkarnikar M. (2008) HBsAg serosurveillance among Nepalese blood donors. Annals of Tropical Medicine and Public Health.2008; 1: 15-18. Doi: 10. 4103/ 1755-6783. 43072.

10. Makroo RN, Salil P, Vashist RP, Shivlal. Trends of HIV infection in the blood donors of Delhi. Indian $J$ Pathol Microbiol. 1996 Apr;39(2):139-42.

11. Gupta N, Kumar V, Kaur A. Seroprevalence of HIV, HBV, HCV and syphilis in voluntary blood donors. Indian J Med Sci. 2004 Jun; 58(6): 255-7.

12. Kakkar N, Kaur R, Dhanoa J. Voluntary donorsneed for a second look. Indian J Pathol Microbiol. 2004 Jul; 47(3):381-3.

13. Arora D, Arora B, Khetarpal A. Seroprevalence of HIV, HBV, HCV and syphilis in blood donors in Southern Haryana. Indian J Pathol Microbiol. 2010 Apr-Jun; 53(2): 308-9. doi: 10. 4103/0377- 4929. 64295.

14. Bhattacharya $\mathrm{P}$, Chakraborty $\mathrm{S}$, Basu SK. Significant increase in HBV, HCV, HIV and syphilis infections among blood donors in West Bengal, Eastern India 2004-2005. Exploratory screening reveals high frequency of occult HBV infection. World J Gastroenterol. 2007July 21; 13:3730-3733. doi:10. 3748 / wjg. v13.i27.3730

15. Sonwane BR, Birare SD, Kulkarni PV. Prevalence of seroreactivity among blood donors in rural population. Indian J Med Sci. 2003 Sep;57(9): 405-7.

16. Singhvi A, Pulimood RB, John TJ, Babu PG, Samuel BU, Padankatti T, Carman RH (1990) The prevalence of markers for hepatitis $\mathrm{B}$ and human immunodeficiency viruses, malarial parasites and microfilaria in blood donors in a large hospital in south India. J Trop Med Hyg.Jun; 93(3):178-82.

17. Drugs and Cosmetics Act 1940 (India). 
18. Srikrishna A, Sitalakshmi S, Damodar P. How safe are our safe donors? Indian J Pathol Microbiol. 1999 Oct; 42(4):411-6.

19. Kakkar N, Kaur R, Dhanoa J. Voluntary donorsneed for a second look. Indian J Pathol Microbiol. 2004 Jul; 47(3):381-3.

20. Garg S, Mathur DR, Garg DK. Comparison of seropositivity of $\mathrm{HIV}, \mathrm{HBV}, \mathrm{HCV}$ and syphilis in replacement and voluntary blood donors in western India. Indian J Pathol Microbiol. 2001 Oct;44(4): 409-12.
21. Pallavi P, Ganesh CK, Jayashree K, Manjunath GV. Seroprevalence and trends in transfusion transmitted infections among blood donors in a university hospital blood bank: a 5 year study. Indian J Hematol Blood Transfus. 2011 Mar;27(1):1-6. doi: 10.1007/s12288010-0047-x. Epub 2010 Dec 14.

22. Behal R, Jain R, Behal KK, Bhagoliwal A, Aggarwal N, Dhole TN. Seroprevalence and risk factors for hepatitis B virus infection among general population in Northern India. Arq Gastroenterol. 2008 Apr-Jun; 45(2):137-40.

\section{How to cite this article?}

Giriyan S.S, Nirala N.K, Agrawal A, Bajpai R. Seroprevalence and trend of Hepatitis B virus infection among the blood donors of North Karnataka: A Nine Year Study.Trop J Path Micro 2017;3(3):248-253.doi: 10.17511/jopm.2017.i3.03. 